\title{
A novel method for multiple bowel injuries: a pilot canine experiment
}

\author{
Jun $\mathrm{Ke}^{1+}$, Weihang $\mathrm{Wu}^{2+}$, Nan Lin ${ }^{2}$, Weijin Yang ${ }^{2}$, Zhicong Cai ${ }^{2}$, Wei Wu ${ }^{2}$, Dongsheng Chen ${ }^{3^{*}}$ and Yu Wang ${ }^{2^{*}}$
}

\begin{abstract}
Background: Intestinal ligation is the cornerstone for damage control in abdominal emergency, yet it may lead to bowel ischemia. Although intestinal ligation avoids further peritoneal cavity pollution, it may lead to an increased pressure within the bowel segments and rapid bacterial translocation. In this study, we showed that severed intestine could be readily reconnected by using silicon tubes and be secured by using rubber bands in a canine model.

Methods: Adult Beagle dogs, subject to multiple intestinal transections and hemorrhagic shock by exsanguination, randomly received conventional ligation vs. silicon tubes reconnecting ( $n=5$ per group). Intestinal transections were carried out under general anesthesia after 24-h fasting. The abdomen was opened with a midline incision. The small intestine was severed at 50,100, and $150 \mathrm{~cm}$ below the Treitz ligament. Hemorrhagic shock was established by streaming blood from the left carotid artery until the mean arterial pressure reached $40 \mathrm{mmHg}$ in $20 \mathrm{~min}$. Fluid resuscitation and surgery began 30 min after the establishment of hemorrhagic shock. Severed intestines were ligated or connected with silicon tubes. Definitive repair was conducted in subjects surviving for at least $48 \mathrm{~h}$.
\end{abstract}

Results: Operation time was comparable between the two groups (39.6 \pm 8.9 vs. $36.6 \pm 7.8$ min in ligation and reconnecting groups, respectively; $p=0.56)$. The time spent in managing each resection was also comparable ( $4.6 \pm 1.1$ vs. $3.8 \pm 0.84 \mathrm{~min} ; p=0.24)$. Blood loss (341.2 \pm 28.6 vs. $333.8 \pm 34.6 \mathrm{ml} ; p=0.48)$, and fluid resuscitation within the first $24 \mathrm{~h}$ $(1676 \pm 200.6$ vs. $1594 \pm 156.5 \mathrm{ml} ; p=0.46)$ were similar. One subject in the ligation group was sacrificed at 36-h due to severe vomiting that led to aspiration. Four remaining dogs in the ligation group received definitive surgery, but two out of four had to be sacrificed at 24-h after definitive repair due to imminent death. All five dogs in the reconnecting group survived for at least a week. Radiographic examination confirmed the integrity of the Gl tract in the reconnecting group. In both groups, plasma endotoxin concentration increased after damage control surgery, but the increase was much more pronounced in the ligation group. Microscopic examination of the involved segment of the intestine revealed much more severe pathology in the ligation group.

Conclusion: The current study showed that the reconnecting resected intestine by using silicon tubes is feasible under emergency. Such a method could decrease short-term mortality and minimize endotoxin translocation.

Keywords: Intestinal injury, Ligation, Reconnecting, Endotoxin translocation

\section{Background}

In critically injured patients, primary repair of gastrointestinal (GI) tract injuries is often not feasible due to hemodynamic instability, coagulopathy, and metabolic acidosis [1-3]. In such cases, management of the GI tract injury

\footnotetext{
*Correspondence: cdsheng315@sohu.com; flyfishwang@hotmail.com ${ }^{\dagger}$ Equal contributors

${ }^{3}$ Department of Anesthesiology, Dongfang Hospital, Xiamen University, Fuzhou, Fujian 350025, China

${ }^{2}$ Department of General Surgery, Dongfang Hospital, Xiamen University,

Fuzhou, Fujian 350025, China

Full list of author information is available at the end of the article
}

is limited to the control of sepsis and hemorrhage [4-8]. Damaged intestines are excised, and the ends are simply ligated to prevent further contamination of the peritoneal cavity. Intestinal continuity is restored in subsequent definitive surgeries.

As the pressure inside the GI tract increases upon ligation, the intestinal wall becomes damaged, and the bacteria translocate into the systemic circulation [9]. Increased pressure also impedes blood supply to the intestine and aggravates the already existing damage [10]. In this study, we examined the effects of home-made 


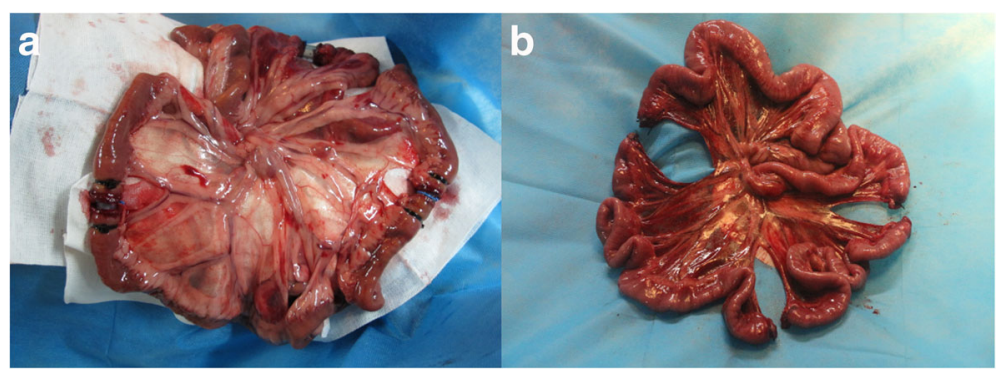

Fig. 1 Representative small intestine segments after ligation (a) and reconnecting (b)

silicon tubes to allow rapid damage control and to restore intestinal continuity in a Beagle dog model of multiple transection of small intestine and hemodynamic shock, with promising preliminary results.

\section{Methods}

\section{Experimental design}

Adult male Beagle dogs $(n=10.13-15 \mathrm{~kg}$; Dasuo Biotech, Chengdu, China) were housed individually at 22$26{ }^{\circ} \mathrm{C}$ with $45-65 \%$ humidity. After $24-\mathrm{h}$ fasting, dogs were anesthetized with ketamine $(10 \mathrm{mg} / \mathrm{kg}$; im). Induction was conducted with bolus i.v. pentobarbital injection $(12-15 \mathrm{mg} / \mathrm{kg})$ and was maintained at a speed of $1 \mathrm{mg} / \mathrm{kg} \mathrm{h}$. A central venous catheter was placed through the left external jugular vein for maintaining anesthesia and blood sampling. A catheter was placed in the right common carotid artery to monitor arterial pressure and heart rate.

The abdomen was opened with a midline incision. The small intestine was severed at 50,100, and $150 \mathrm{~cm}$ below the ligament of Treitz. Then the abdominal cavity was temporarily closed with towel forceps. Hemorrhagic shock was induced with bleeding from the jugular artery to maintain mean arterial pressure (MAP) at $40 \mathrm{mmHg}$ in $20 \mathrm{~min}$. Fluid resuscitation with Ringer's solution was initiated $30 \mathrm{~min}$ after the hemorrhagic shock. Severed intestine was managed with conventional ligation or reconnection using a silicon tube (Xiangshu, Shanghai, China) ( $n=5$ for each, Fig. 1). The tube was inserted 2$3 \mathrm{~cm}$ into the edge of resection and was secured with rubber bands. A gastrostomy catheter (16 F) was placed for nutritional support later.

Definitive surgery was carried out at $48 \mathrm{~h}$ in dogs that survived beyond $48 \mathrm{~h}$. Prior to definitive operation, the upper digestive tract was examined using imaging analysis of Meglumine Diatrizoate. $24 \mathrm{~h}$ after definitive surgery, the remaining animals in both groups were given nutritional support through a gastrostomy catheter (250 cal/day, in $250 \mathrm{ml}$ volume).

\section{Outcome assessment}

Plasma endotoxin concentration was determined by an enzyme-linked immunosorbent assay (ELISA) kits from Jinshanchuan (Beijing, China). Tissues were fixed in 10\% formalin for $24 \mathrm{~h}$ and embedded in paraffin, and were processed for light microscopy with hematoxylin and eosin staining. For transmission electron microscopy (TME), tissues (at 50-cm distal to ligament of Treitz) were fixed in $4 \%$ glutaraldehyde and 1\% paraformaldehyde, dehydrated, and embedded in Spurr resin. Ultrathin sections $(2-3 \mathrm{~mm})$ were stained with citrate. Photographs were obtained with a Philips EM208S transmission electron microscope (Philips; Eindhoven, Netherlands). The magnification of images was $10 \times 1000$.

\section{Statistical methods}

Continuous variables are presented as means \pm standard deviation and analyzed with Student's $t$ test or analysis of variance (ANOVA) of repeated measure with Statistical Package (SPSS 20.0 for windows, SPSS Inc., Illinois, USA). A probability of less than 0.05 was accepted as significant.

The Ethics Committee of Dongfang Hospital approved the study.

\section{Results}

The current study showed practically zero short-term mortality in dogs receiving reconnecting after multiple

Table 1 Plasma endotoxin concentration after ligation and reconnecting

\begin{tabular}{llllll}
\hline & $0 \mathrm{~h}$ & $2 \mathrm{~h}$ & $4 \mathrm{~h}$ & $8 \mathrm{~h}$ & $24 \mathrm{~h}$ \\
\hline Reconnecting & $3.95 \pm 0.75$ & $25.19 \pm 21.50$ & $39.43 \pm 22.86$ & $55.55 \pm 23.72$ & $46.50 \pm 19.22$ \\
Ligation & $3.98 \pm 0.60$ & $51.78 \pm 23.81$ & $85.26 \pm 26.89$ & $96.89 \pm 19.82$ & $102.27 \pm 20.03$ \\
$P$ value & 0.94 & 0.10 & $0.02^{*}$ & $0.01^{*}$ & $<0.01^{*}$ \\
\hline
\end{tabular}

Note: values were expressed as mean $\pm \mathrm{SD} ;{ }^{*}$ refers to the $p$ value between two groups was statistically significant, ANOVA of repeated measures 


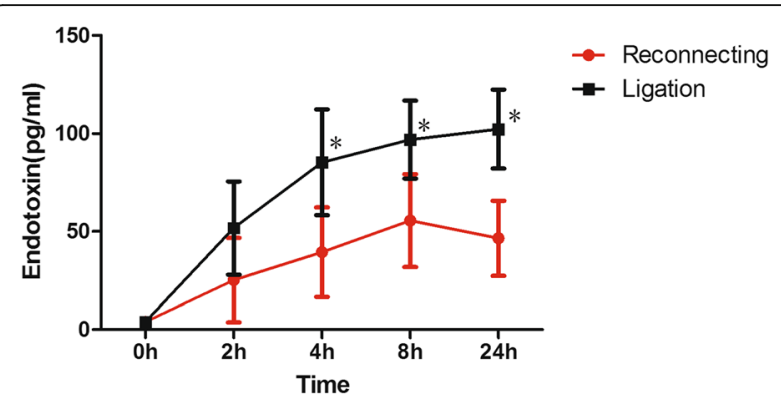

Fig. 2 Plasma endotoxin concentration after ligation and reconnecting. ${ }^{*}$ refers to the $p$ value between two groups was statistically significant

transections of the small intestine, as well as much lower plasma endotoxin concentration.

Operation time of the damage control operation was comparable between the two groups (39.6 \pm 8.9 vs. $36.6 \pm 7.80 \mathrm{~min}$ in the ligation and reconnecting groups, respectively; $p=0.56$ ). The time spent in managing each resection was comparable $(4.6 \pm 1.1$ vs. $3.8 \pm 0.8 \mathrm{~min}$; $p=0.24)$. Blood loss $(341.2 \pm 28.6$ vs. $333.8 \pm 34.6 \mathrm{ml}$; $p=0.48$ ) and fluid resuscitation within the first $24 \mathrm{~h}$ $(1676 \pm 200.6$ vs. $1594 \pm 156.5 \mathrm{ml} ; p=0.46)$ were similar between the two groups.

Plasma endotoxin concentration increased after the surgery in both groups, but was much more pronounced in the ligation group (Table 1; Fig. 2). One dog in the ligation group was sacrificed after $36 \mathrm{~h}$ due to severe vomiting that led to aspiration. The remaining four dogs in the ligation groups received definitive operation, but two had to be sacrificed within $24 \mathrm{~h}$ after definitive repair due to imminent death. Post-mortem analysis revealed large amount of ascites in abdominal cavity. All five dogs in the reconnecting group survived for at least a week after the definitive operation.

Microscopic examination of the involved intestine revealed much more severe damage, including sloughing of surface epithelium, massive intraepithelial neutrophil infiltration and necrosis, in the ligation group vs. the reconnecting group (light microscopy in Fig. 3; TEM in
Fig. 4). Radiographic examination of the upper digestive tract at $48 \mathrm{~h}$ in the reconnecting group showed the contrast medium flowed through the intestine (Fig. 5).

\section{Discussion}

Patients with severe multiple enteric injuries often had severe comorbid conditions (such as hemodynamic shock). Currently, damage control surgery is to carry out ligation of severed/injuried GI tract $[4,7,8]$. Aggravated abdominal cavity contamination and bleeding can be easily controlled; however, continuing loss of fluids from the vascular compartment to the interstitial and third spaces leads to hemodynamic imbalance [11]. The ligations also elevate pressure within the bowel segments left in discontinuity and facilitate the development of pressure-related complications, such as bacterial translocation [12-14]. Consistent with a previous study [15], we observed rapid endotoxin translocation in the current study. Attempts have been made by previous studies to address the issue, such as an intraluminal drainage system to reduce intraluminal pressure [16]. Procedures required, however, are complex and time consuming.

In this study, we showed feasibility of reconnecting severed small intestine with silicon tubes. The method allowed rapid re-establishment of GI tract continuity. Comparison with ligation indicated that reconnecting could reduce bacteria translocation and tissue damage to small intestine in the involved segments. More importantly, short-term mortality (within a week after definitive surgery) is reduced to practically zero.

Time is of essence in definitive surgery; physicians must weigh risks vs. benefits $[6,17]$. Ligation is considered a gold standard that could stabilize the physiological conditions of most patients. Definitive surgery, however, must be performed within a short period of time. Otherwise, patient's condition will deteriorate [13, $18]$. In the current series, we could complete the procedure within a very short period of time, without failure of this simple device (such as slipping-out of the tubes).

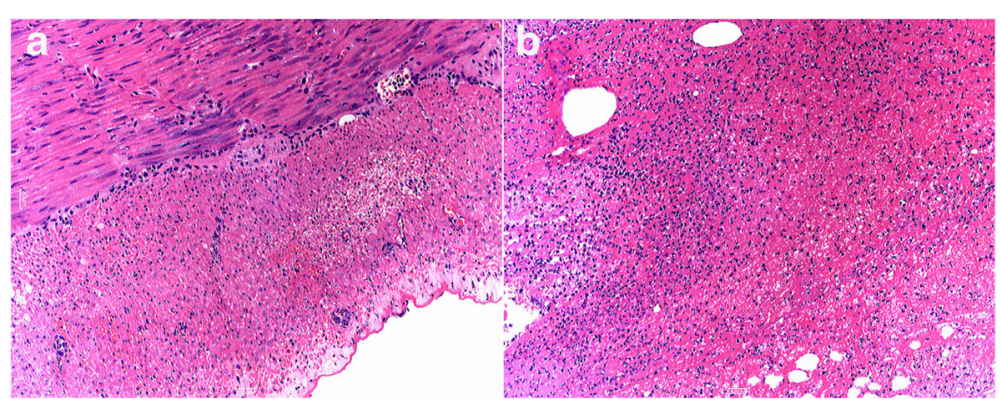

Fig. 3 Intestinal mucosa (at 50-cm distal to ligament of Treitz) in dogs subjected to ligation (a) and reconnecting (b), at $48 \mathrm{~h}$ under light microspcopy $(\times 100)$ 


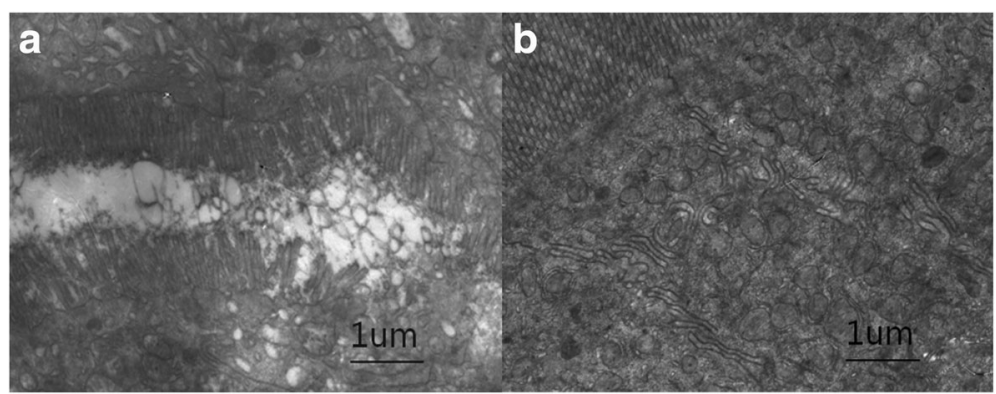

Fig. 4 Transmission electron microscopy examination of the bowel (at 50-cm distal to ligament of Treitz) in dogs subjected to ligation (a) and reconnecting (b) at $48 \mathrm{~h}(10 \times 1000)$

Another critical issue in the management of severe abdominal trauma is preserving the function of the gastrointestinal tract. Primary anastomosis could be hazardous because of the prolonged operation time and compromised hemodynamic conditions [4-7]. In this regard, temporally reconnecting transected intestines restored the continuity and the function of the GI tract, as evidenced by radiographic examination at $48 \mathrm{~h}$ after the reconnection.

We suspect in the future, this tubes system will be applied to patients with bowels ruptured, who be allowed for damage control surgical conditions. However,

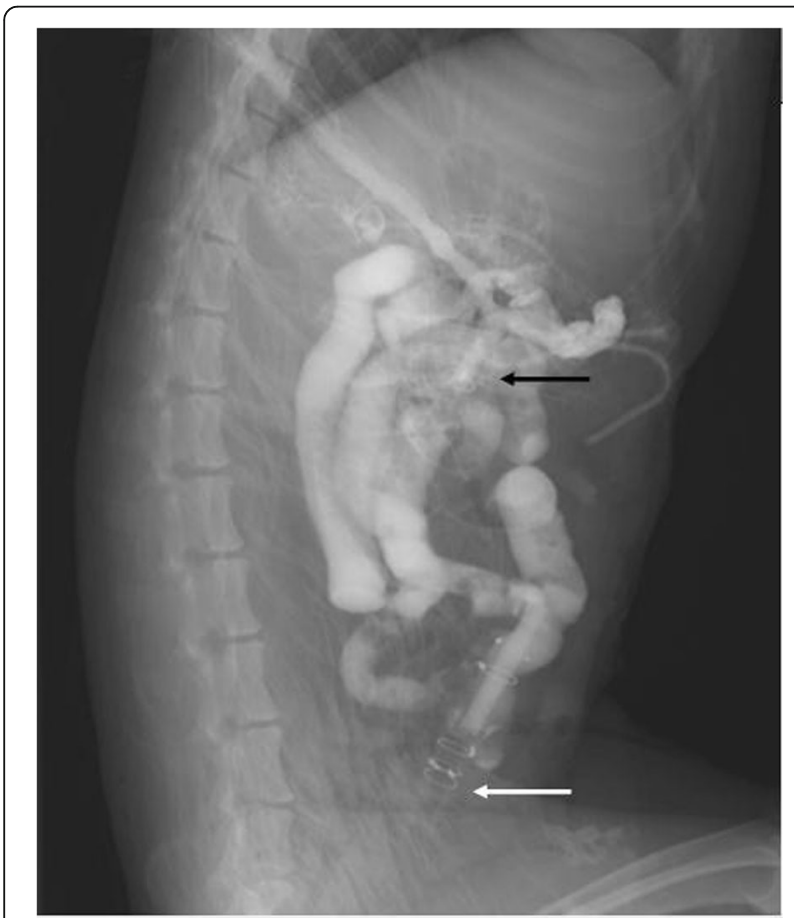

Fig. 5 Radiographic examination of the upper digestive tract in a dog subjected to reconnecting at $48 \mathrm{~h}$ showed the contrast medium flowed smoothly through the intestine. There were no sign of air fluid level and swollen or obstructed intestines. Note: black arrow refers to proximal intestines; white arrow refers to distal intestines injuries in clinical settings are typically far more complex than those modeled in the current study. Clearly, the current study is a proof-of-concept in nature and requires further studies in animal studies before applying to human subjects.

\section{Conclusions}

Reconnecting transected small intestine with silicon tubes and tuber bands is a viable method of damage control. Further studies are required to validate the results of this preliminary study.

\section{Abbreviations}

Gl: Gastrointestinal; MAP: Mean arterial pressure; TME: Transmission electron microscopy

\section{Acknowledgements}

The authors thank the Animal Experimental Center and the Department of Pathology at Dongfang Hospital for technical assistance.

\section{Funding}

This study was supported by the Key Project of Nanjing Command (14ZX25), Key Medicine Project of PLA (CNJ15J004), Cooperate Project of Fujian Province (2015l0013), and Key Project of Nanjing Command (15DX024).

\section{Availability of data and materials}

The datasets during and/or analyzed during the current study are available from the

corresponding author on reasonable request.

\section{Authors' contributions}

YW and DC designed this study. JK, NL, WY, ZC, and WWH performed the experiments. WWH, ZC, and WW collected and analyzed the data. YW and DC provided additional support, including review of the manuscript. JK and WWH wrote the manuscript, which was critically reviewed and revised by YW and DC. All of the authors read and approved the final manuscript.

Ethics approval and consent to participate

The study protocol was approved by the Ethics Committee of Dongfang Hospital.

\section{Consent for publication}

Not applicable.

\section{Competing interests}

The authors declare that they have no competing interests. 


\section{Publisher's Note}

Springer Nature remains neutral with regard to jurisdictional claims in published maps and institutional affiliations.

\section{Author details}

${ }^{1}$ Department of Gastroenterology, Dongfang Hospital, Xiamen University, Fuzhou, Fujian 350025, China. 'Department of General Surgery, Dongfang Hospital, Xiamen University, Fuzhou, Fujian 350025, China. ${ }^{3}$ Department of Anesthesiology, Dongfang Hospital, Xiamen University, Fuzhou, Fujian 350025, China.

Received: 25 June 2017 Accepted: 29 August 2017

Published online: 15 September 2017

\section{References}

1. Smith IM, Beech ZK, Lundy JB, Bowley DM. A prospective observational study of abdominal injury management in contemporary military operations: damage control laparotomy is associated with high survivability and low rates of fecal diversion. Ann Surg. 2015;261:765-73.

2. Burch J, Ortiz VB, Richardson RJ, Martin RR, Mattox KL, Jordan GL Jr. Abbreviated laparotomy and planned reoperation for critically injured patients. Ann Surg. 1992:215:476.

3. Lier $\mathrm{H}, \mathrm{Krep} \mathrm{H}$, Schroeder S, Stuber F. Preconditions of hemostasis in trauma A review. The influence of acidosis, hypocalcemia, anemia, and hypothermia on functional hemostasis in trauma. J Trauma Acute Care. 2008;65:951-60.

4. Olofsson P, Vikström T, Nagelkerke N, Wang J, Abu-Zidan F. Multiple small bowel ligation compared to conventional primary repair after abdominal gunshot wound with haemorrhagic shock. Scand J Surg. 2009;98:41-7.

5. Chovanes J, Cannon JW, Nunez TC. The evolution of damage control surgery. Surg Clin N Am. 2012;92:859-75.

6. Waibel BH, Rotondo MM. Damage control surgery: it's evolution over the last 20 years. Rev Col Bras Cir. 2012;39:314-21.

7. Weber D, Bendinelli C, Balogh Z. Damage control surgery for abdominal emergencies. Brit J Surg. 2014;101:e109-18.

8. Rotondo MF, Schwab CW, McGonigal MD, Phillips GR, Fruchterman TM, Kauder DR, et al. 'Damage control': an approach for improved survival in exsanguinating penetrating abdominal injury. J Trauma Acute Care. 1993;35:375-83.

9. Wang P, Wei X, Li Y, Li J. Influences of intestinal ligation on bacterial translocation and inflammatory response in rats with hemorrhagic shock: implications for damage control surgery. J Investig Surg. 2008;21:244-54.

10. Wu J, Ding W, Liu X, Kao X, Xu X, Li N, et al. Intraintestinal drainage as a damage control surgery adjunct in a hypothermic traumatic shock swine model with multiple bowel perforations. J Surg Res. 2014;192:170-6.

11. Plante GE, Chakir M, Ettaouil K, Lehoux S, Sirois P. Consequences of alteration in capillary permeability. Can J Physiol Pharm. 1996;74:824-33.

12. Zanoni FL, Benabou S, Greco KV, Moreno ACR, Cruz JWMC, Filgueira FP, et al. Mesenteric microcirculatory dysfunctions and translocation of indigenous bacteria in a rat model of strangulated small bowel obstruction. Clinics. 2009;64:911-9.

13. Raeburn CD, Moore EE, Biffl WL, Johnson JL, Meldrum DR, Offner PJ, et al. The abdominal compartment syndrome is a morbid complication of postinjury damage control surgery. Am J Surg. 2001;182:542-6.

14. Baker JW, Deitch EA, Li M, Berg RD, Specian RD. Hemorrhagic shock induces bacterial translocation from the gut. J Trauma Acute Care. 1988;28:896-913.

15. Deitch EA, Berg R, Specian R. Endotoxin promotes the translocation of bacteria from the gut. Arch Surg. 1987;122:185-90.

16. Ji W, Ding W, Liu X, Kao X, Xu X, Li N, et al. Intraintestinal drainage as a damage control surgery adjunct in a hypothermic traumatic shock swine model with multiple bowel perforations. J Surg Res. 2014;192:170-6.

17. Faria GR, Almeida AB, Moreira H, Barbosa E, Correia-da-Silva P, Costa-Maia J. Prognostic factors for traumatic bowel injuries: killing time. World J Surg. 2012;36:807-12.

18. Enochsson L, Nylander G, Öhman U. Effects of intraluminal pressure on regional blood flow in obstructed and unobstructed small intestines in the rat. Am J Surg. 1982;144:558-61.

\section{Submit your next manuscript to BioMed Central and we will help you at every step:}

- We accept pre-submission inquiries

- Our selector tool helps you to find the most relevant journal

- We provide round the clock customer support

- Convenient online submission

- Thorough peer review

- Inclusion in PubMed and all major indexing services

- Maximum visibility for your research

Submit your manuscript at www.biomedcentral.com/submit 